\title{
Relation Hepcidin with Renal Failure
}

\author{
Dr. Rusul Arif Abd Ali \\ Department Medical Laboratory Technique, Imam Jaffar al-Sadeq University, Iraq \\ *e-mail: rusulaa.sc12p@uokufa.edu.iq
}

\begin{abstract}
Renal failure refers to a condition where the kidneys lose their normal functionality, which may be due to various factors including infections, auto immune diseases, diabetes and other endocrine disorders, cancer, and toxic chemicals. It is characterized by the reduction in the excretory and regulatory functions of kidney. Biochemically, it is typically detected by an elevated serum creatinine. In the science of physiology it is described as a decrease in glomerular filtration rate (GFR). Hepcidin is a peptide produced primarily in the liver. Its mature form consists of 25 amino acids with a calculated mass of $2.8 \mathrm{kDa}$. Hepcidin has a key role in iron homeostasis by interacting with ferroportin. Hepcidin is the regulator of iron homeostasis in humans and other mammals. In humans, HAMP is the gene that encodes for hepcidin. 25-amino acid peptide was first identified in human urine and plasma. This peptide contains four disulfide bonds. It is synthesized, processed and secreted primarily by hepatocytes. In vitro, human hepcidin has anti-bacterial and antifungal activities. The 25-amino acid peptide of hepcidin is secreted by the liver, which seems to be the "master regulator" of iron metabolism.
\end{abstract}

Keywords: Renal Failure, glomerular filtration rate (GFR), Hepcidin

Article Information

Received: November 20, 2020; Online: December 4, 2020

\section{INTRODUCTION}

The major part of urinary system are the kidneys, the urinary bladder, two ureters and the urethra. Each component of urinary system has unique function .Urine is manufactured in the kidney, the urinary bladder serve as temporary storage reservoir for urine. The ureter transports urine from the kidney to the bladder. The urethra transports the urine from the bladder to outside of the body (Guyton and Hall, 2011).

Urinary system function includes regulation of body fluid, removal of metabolic waste product, regulation of volume and chemical made up of blood plasma and excretion of toxin. The main source of water gain are drinking and ingesting fluid such as water contained in the food and water product as by product of metabolic processes. The main source of water loss are urine formation, evaporation from the lungs (breathing), evaporation from the skin (sweating), and through feces (Premkumar, 2004).

\section{Types of Renal Failure}

\section{Acute Renal Failure}

This is characterized by sudden impairment of renal function demonstrated by rapid and steadily increasing azotemia excreted (accumulation in the blood of toxic products normally by the kidneys) with or without oliguria (decreased urine output) (Klahr and Miller, 1998). The causes of ARF include:

a. Acute renal failure resulting from decreased blood supply to the kidneys; this condition is often referred to as prerenal acute renal failure to reflect the fact that the abnormality occurs as a result of an abnormality originating outside the kidneys. For example, prerenal acute renal failure can be a consequence of heart failure with reduced cardiac output and low blood pressure or conditions associated with diminished blood volume and low blood pressure, such as severe hemorrhage. 
b. Intrarenal acute renal failure resulting from abnormalities within the kidney itself, including those that affect the blood vessels, glomeruli, or tubules.

c. Postrenal acute renal failure, resulting from obstruction of the urinary collecting system anywhere from the calyces to the outflow from the bladder. The most common causes of obstruction of the urinary tract outside the kidney are kidney stones, caused by precipitation of calcium, urate, or cystine (Guyton and Hall, 2006).

\section{Physiologic changes of acute renal failure:}

Physiologic Changes of Acute Renal Failure include the following: (Guyton and Hall, 2006)

a. Edema: result from accumulation of fluid in the blood and the body cavity.

b. Hypertension: due to saline stress and increase the size of bodily fluids.

c. Hyperkalemia: high blood potassium concentration.

d. Anuria: lack of micturition (in severe cases).

e. Acidosis: increased blood $\mathrm{pH}$.

f. The anemia and high blood phosphate concentration (Hyperphosphatemia) they are less frequent in the case of acute renal failure Compared with chronic renal failure (Schrier, 2007).

\section{Chronic Renal Failure}

CKD can be define as kidney damage or GFR $<60 \mathrm{ml} / \mathrm{min} / 1.73 \mathrm{~m} 2$ for 3 months or more, irrespective of cause. Kidney damage in many kidney diseases can be ascertained by the presence of albuminuria, defined as albumin-tocreatinine ratio $>30 \mathrm{mg} / \mathrm{g}$ in two of three spot urine specimens (Levey et al., 2005). Table (2.1) characteristics between acute and chronic renal failure. Chronic kidney disease has been classified into various stages for the purpose of prevention, early identification of renal damage and institution of preventive measures for progression of the primary damage and appropriate guidelines for instituting management for prevention of complications in severe CKD (Vijayakumar et al., 2007).

\begin{tabular}{|l|l|c|}
\hline $\begin{array}{l}\text { Diagnostic } \\
\text { Feature }\end{array}$ & Acute & Chronic \\
\hline $\begin{array}{l}\text { Duration } \\
\text { pathogenicity }\end{array}$ & short & long \\
\hline
\end{tabular}

\begin{tabular}{|l|c|c|}
\hline $\begin{array}{l}\text { Diagnostic } \\
\text { Feature }\end{array}$ & Acute & Chronic \\
\hline Skin itching & No & Yes \\
\hline Anemia & Rare & common \\
\hline $\begin{array}{l}\text { Kidney } \\
\text { atrophy }\end{array}$ & No & Yes \\
\hline Bone disease & No & yes \\
\hline
\end{tabular}

(Al-Fahham, 2011).

\section{Causes of chronic renal failure}

There are many reasons that are involved in the development of chronic renal failure.Varied these reasons as the physiological links to kidney with the other member devices and somatic organs. The spread of these different causes and attributed its influence in the events of renal failure depending on the geographical area (Levy et al., 2005). The most important are:

1. Metabolic disorders :

It is absolutely the most important of diabetes mellitus. Diabetes which is reason in chronic renal failure events in many regions around the world (Levy et al., 2005), and especially in the United States as it is the first cause patients. Study indicate that diabetes causes about $44 \%$ of cases of chronic renal failure in the United States in 2007 (Burrows et al., 2010) .

2. Glomerulonephritis:

Australia and New Zealand recorded the highest rate of kidney failure generated by inflammation of the renal glomerulus responsible for $27 \%$ of the cases of renal failure in Europe (Levy et al., 2005).

3. Hypertension:

Is second reason in the events of chronic renal failure in the United States of America (Ravera et al., 2006), while representing the main reason for the African countries responsible for $54 \%$ of the cases of renal failure (Chhetri et al., 2008).

4. Urinary tract obstruction:

The result of an enlarged prostate and urinary tract stones or kidney stones (Levy et al., 2005).

5. Some chronic inflammation: Pyelonephritis (NIDDK, 2007).

6. Kidney Birth defects: as kidney atrophy. (Boon et al., 2006).

7. Some genetic diseases: as polycystic kidney disease (Di Giulio et al., 2007).

8. Kidney poisoning by heavy metals such as lead and mercury (Davidson et al., 2005) 


\section{Clinical signs \& Symptoms}

Studies reported a wide range of clinical symptoms that appear on patients with chronic renal failure but it's not necessary that meets all of these signs and symptoms in a patient kidney failure. However it may vary depending on the stage of the disease, its causes and its complications. The most important signs and symptoms are:

1. Uremia: increase concentration of urea and creatinin in blood.

2. Fatigue and weakness.

3. Loss of appetite: lead to malnutrition and weight loss.

4. Nausea and Vomiting.

5. Noctoria: increased urination night.

6. Headache and Back Pain.

7. Hypertension: Due to accumulation of fluid and salts.

8. Oedema In limbs, face, hands, feet and lungs.

9. Loin pain in cases of failure resulting from the presence of kidney stone.

10. Anemia.

11. Dark skin and Itching.

12. Nervousness and Inability to concentrate.

13. Depression and decrease Libido.

14. Muscles Cramp or Paralysis.

(Di Giulio et al., 2007; Yazar and Kayhan, 2010).

\section{Hepcidin}

The current scientific evidence suggests that hepcidin is a central regulatory hormone, and its main action is to regulate systemic iron homeostasis (Ashby et al., 2009). The synthesis of hepcidin is greatly stimulated by inflammation or by iron overload. Evidence from transgenic mouse models indicates that hepcidin is the predominant negative regulator of iron absorption in the small intestine, iron transport across the placenta, and iron release from macrophages. The key role of hepcidin is confirmed by the presence of nonsense mutations in the hepcidin gene, homozygous in the affected members, in 2 families with severe juvenile hemochromatosis.

The evidence shows that deficient hepcidin response to iron loading may contribute to iron overload even in the much milder common form of hemochromatosis, from mutations in the HFE gene.
In anemia of inflammation, hepcidin production is increased up to 100- fold and this may account for the defining feature of this condition, sequestration of iron in macrophages. The discovery of hepcidin and its role in iron metabolism could lead to new therapies for hemochromatosis and anemia of inflammation (Tomas, 2003). In addition to iron stores and inflammation, anemia and hypoxia also affect iron metabolism.

These stimuli would be expected to decrease hepcidin production and remove the inhibitory effect on iron absorption and iron release from macrophages so that more iron is available for compensatory erythropoiesis (Weinstein et al., 2002).

During studies of antimicrobial properties of various human body fluids, Park et al isolated a new peptide from human urine and named it hepcidin, based on its site of synthesis (the liver, hepcidin) and antibacterial properties in vitro. (Park et al., 2001) independently Krause et al., isolated the same peptide from plasma ultrafiltrate and named it LEAP-1 (liverexpressed antimicrobial peptide).

The major hepcidin form was a cationic peptide with 25 amino acid residues and 4 disulfide bridges. In humans, the peptide is derived from the $\mathrm{C}$-terminus of an 84-amino acid prepropeptide, encoded by a 0.4 -kilobase (kb) mRNA generated from 3 exons of a $2.5-\mathrm{kb}$ gene on chromosome 19.

Compared with other antimicrobial peptides whose sequences have evolved rapidly and vary significantly even between closely related mammalian species, the evolution of hepcidin was constrained and hinted at the possibility that this peptide might specifically interact with other conserved macromolecules. Hepcidin composition and its site of -synthesis was reminiscent of drosomycin, a 4-disulfide insect defensin synthesized in the fat body of drosophila (the equivalent of the liver) in response to infections.

In the course of these initial studies, one of the urine donors developed a systemic infection, and the concentration of hepcidin was increased about 100-fold in the acute urine samples. This observation reinforced the notion that hepcidin was a mediator of innate immunity (Krause et al., 2000, Al-Hisnawi et al .,2014). 


\section{DISCUSSION}

The result shows significant increase in hepcidin levels in both males and females in patients with chronic renal failure as compared with their parallel control groups. This result agree with the results obtained by (Jolanta et al; 2006).

Hepcidin is a peptide whose production by hepatocytes is modulated in response to anemia, hypoxia, or inflammation, Hepcidin could also act as an indicator of functional iron deficiency in these patients. Cross-sectional study was performed to assess hepcidin correlations with renal function, iron status in patients with chronic renal failure. In 2001, a peptide with antimicrobial properties was discovered, named hepcidin (Park et al., 2001; Pigeon et al., 2001).

Hepcidin turned out to be a key regulator of iron homeostasis in humans. It induces internalization and degradation of ferroportin, which is a cellular iron exporter on enterocytes, macrophages and hepatocytes.

The expression of hepcidin is regulated in response to iron administration, erythropoietic demand, hypoxia and inflammatory signals (Babitt et al., 2010; Kroot et al., 2011). Hepcidin-25 amino acid $(2.8 \mathrm{kD})$ is the bioactive form of hepcidin and is mainly protein bound, whereas hepcidin-20 and hepcidin- 22 are its isoforms with unknown biological function (Kroot et al., 2011).

All isoforms are excreted from the body with the urine. In patients with chronic kidney disease (CKD), hepcidin levels are elevated (Peter et al., 2011; Zartsky et al., 2009). High hepcidin levels result in limited absolute and functional iron availability due to decreased iron uptake from the gut and decreased iron release from reticuloendothelial and hepatocyte stores (Coyne, 2011). In addition, hepcidin exhibits a direct inhibitory effect on erythroid progenitor proliferation at low erythropoietin concentrations (Dallalio et al., 2006).

Therefore, in CKD patients, enhanced hepcidin levels may contribute to diminished iron availability and an impaired ESA response. Subsequently, it has been hypothesized that lowering hepcidin levels may result in improved (functional) iron availability and an enhanced response to ESA (Besarab, 2010).

It is well known that iron malabsorption in the gastrointestinal tract is an important cause of iron deficiency in chronic dialysis patients (Besarab, 2010). And that iron absorbed from dietary sources is often inadequate to meet requirements for erythropoiesis in HD patients and result decrease $\mathrm{Hb}$ concentration lead to anemia in CRF patient (Eschbach et al., 1977) . The hepcidin concentration can be reduced over one dialysis-session, HD and peritoneal dialysis (Peter et al., 2011)

However, hepcidin levels already returned back to baseline within one hour after a dialysis session.(Kuragano et al .,2010) This might be explained by removal of unbound, free hepcidin, whereas hepcidin is bound with high affinity to $\alpha 2$-macrogloblin (and more non-specific and with less affinity to albumin) (Peslova et al ., 2010). In hemodialyzed patients hepcidin, correlated significantly with triglycerides, albumin, creatinine, urea, residual renal function, (Jolanta et al; 2006).

\section{CONCLUSIONS}

From the current study, it can be concluded that:

1. Correlation between hepcidin and ferritin were consistently positive and statistically significant. Values consistent with inflammation as cause for elevation of hepcidin irrespective to its regulation by iron status.

2. This study supports the role for hepcidin as biochemical risk factors of CRF.

3. The study shows a positive correlation between hepcidin and (fasting Blood sugar) in both male and female patients with (CRF).

\section{RECOMMENDATION}

1. Study of the properties of the relationship hepcidine with Immunoglobulin (immunity component).

2. Study of the properties of the relationship hepcidine with free redicalmand Antioxidant.

3. Study of the properties of the relationship hepcidine with Bone marrow biopsy.

\section{REFERENCES}

Al-Fahham,A.A.(2011) A Study of Som Physiological and Biochemichal Changes in Patients With Cronic Renal Failure Undergoing Hemodialysis in Al-Najaf Governorate.(Master Thesis). 
Ashby, D.R.; Gale, D.P and Busbridge, M . (2009). Plasma hepcidin levels are elevated but responsive to erythropoietin therapy in renal disease". Kidney Int., 75: 976-81.

Babitt, J.L.; Lin, H.Y. (2010) Molecular mechanisms of hepcidin regulation: implications for the anemia of CKD. AmJKidney Dis. , 55: 726-741.

Besarab, A.; Coyne, D.W. (2010) .Iron supplementation to treat anemia in patients with chronic kidney disease. Nat Rev Nephrol., 6: 699-710. Blood., 99:3505-3516.

Boon , N.; Colledge, N.R.; and Walker, B. R. (2006). Davidsons principles and practice $.20^{\text {th }}$ Ed Churchill Livingstone, Philadelphia, USA.

Brady, H. R .;Singer, G.G. (1995). Acute renal failure . Lancet; 346:1533- 40.

Burrows, N.R.; Hora, I.; Chso, Gerzoff, R.B. and Geiss, L.S.(2010).Incidence of end stage Renal disease Attributed to Diabetes Among Person With Diagnosed Diabetes-United States and Puerto Rico ,1996-2007. JAMA ., 304:2688-90.

Chhetri, P.K.; Manandhar, D.N.; Bhattarai, S.P.; Pahari , L.R . and Shrestha, R. (2008). Chronic Kidney Disease 5on Hemodialysis in Nepal Medical College. Nepal Med COLL J., 10:8-10.

Collins, A.J .;Kasiske, B. ;Herzog ,C. (2003). Excerpts from the United States Renal Data System .Annual data report : atlas of end-stage renal disease in the United States .Am J Kidney Dis;42 (6 suppl 5):S1-S226.

Coyne, D.W. (2011) . Hepcidin: clinical utility as a diagnostic tool and therapeutic target. Kidney Int., 80: 240-244.

Davidson, A.M. ; Cameron, J.S.; and Ypersele , C.V. (2005) . Oxford Textbook of Clinical Nephrology. $3^{\text {rd }}$ ed Oxford university Press Inc, New York, USA.

DiGiulio , M .Jackson, and Keogh, J. (2007). Medical-surgical nursing: demystified .McGraw-Hill Companies, Inc, USA.

Eschbach, J.W. ; Cook, J.D.; Scribner, B.H. et al. (1977). Iron balance in hemodialysis patients. Ann Intern Med.,87: 710-713.

Feest, T.G.; Round, A.; Hamad, S. (1993). Incidence of sever acute renal failure in adults results of community based study . BMJ ., $306: 481-3$.
Finn, W.F. (1993). Recovery from acute renal failure in. Lazarus JM , Brenner BM ,eds. Acute renal failure . 3d Ed. New York : Churchill Livingstone ., 553 -96.

Ganz ,T .(2003). Hepcidin, a key regulator of iron metabolism and mediator of anemia of inflammation. Blood 102 (3): 783-8.

Guyton ,A.C. and Hall, J.E. (2006) .Textbook of medical physiology . $11^{\text {th }}$ Ed. Elsevier Saunders . Philadelphia , USA.

Guyton, A.C. and Hall, J.E. (2011). Textbook of Medical Physiology, 12th Edition, Saunders, Philadelphia, USA.

Herzog, C., Asinger, R., Berger, A., Charytan, D., D ez J., Hart, R., Eckardt , K., Kasiske, B., McCullough, P., Passman, R., DeLoach, S., Pun, P., and Ritz, E. 2011. Cardiovascular disease in chronic kidney disease. A clinical update from Kidney Disease: Improving Global Outcomes (KDIGO). International Society of Nephrology. 1038(10): 223-30

Jolanta, M.; Jacek, S. ;Malyszko, K.; Pawlak, and Michal M.( 2006). Hepcidin, Iron Status, and Renal Function in Chronic Renal Failure, Kidney Transplantation, and Hemodialysis. American Journal of Hematology 81:832837.

Klahr, S .; Miller, S. (1998). "Acute oliguria ". $N$ Engl J Med., 338 :671-5.

Krause, A.; Neitz, S.; Magert, H.J. (2000). LEAP1 , a novel highly disulfide-bonded human peptide, exhibits antimicrobial activity. FEBS Lett. , 480: 147-50.

Krause, A.; Neitz, S.; Magert, H.J. (2000). LEAP1 , a novel highly disulfide-bonded human peptide, exhibits antimicrobial activity. FEBS Lett. , 480: 147-50.

Kroot ,J.J.; Tjalsma, H.; Fleming ,R.E. (2011) . Hepcidin in human iron disorders: diagnostic implications. Clin Chem., 57: 1650-1669.

Kuragano, T.; Shimonaka, Y.; Kida, A. (2010) . Determinants of hepcidin in patients on maintenance hemodialysis: role of inflammation. AmJNephrol., 31: 534-540.

Levy, J.; Morgan, J.; and Brown, E. (2005) .Oxford Handbook of Dialysis, $2^{\text {nd }}$ ed . Oxford Univercity press, UK.

Meyer, T.W. \& Hostetter, T.H.(2007). Uremea .N. Engl. J. med., 357(13):1316-1325.

NIDDK (National Institute of Diabetes and Digestive and Kidney Disease) (2007). 
Pyelonephritis (Kidney Infection) in adult .NIH, U.S Department of Health and Human Services, online Publication at www.Kidney .niddk .nih gov.

Nolan, C.R.; Anderson, R.J. (1998). Hospitalacquired acute renal failure .Jam Soc Nephrol .9: 710-12.

Park, C.H.;Valore, E.V.; Waring, A.J.; Ganz ,T.( 2001). Hepcidin, a urinary antimicrobial peptide synthesized in the liver. $J$ Biol Chem. ,276: 7806-7810.

Peslova, G.; Petrak, J.; Kuzelova, K. (2009) . Hepcidin, the hormone of iron metabolism, is bound specifically to alpha-2-macroglobulin in blood. Blood., 113: 6225-6236.

Peters, H.P.E.; Laarakkers, C.M.M.; Swinkels, D.W. (2010) .Serum hepcidin-25 levels in patients with chronic kidney disease are independent of glomerular "ltration rate. NephrolDialTransplant., 25: 848-853.

Pigeon, C.; Ilyin, G.; Courselaud, B. A. (2001) .New mouse liver-speci"c gene, encoding a protein homologous to human antimicrobial peptide hepcidin, is overexpressed during iron overload. J Biol Chem. , 276: 7811-7819.

Premkumar, K. (2004). The massage connection: anatomy \&physiology. 2nd Ed; Lippincott Williams \& Wilkins, Philadelphia, USA

Ravera, M. R .e.M.; Deferrari, L.; vettoretti, S.; and Deferrari, G. (2006). Importance of blood pressure control in chronic Kidney disease on Hemodialysis . Experientia., 31:980-981.

Rusul ,A.A.A. AL-Hisnawi and Haider, s.(2014). A study of some biochemical changes in patients with chronic renal failure undergoing hemodialysis. Int.J.Curr.Microbiol.App.Sci . 3(5): $581-586$
Salvador Lopez-Giacoman, Magdalena Madero.(2014). Biomarkers in chronic kidney disease, from kidney function to kidney damage. World J Nephrol .6; 4(1): 57-73.

Schrier, E.S. (2007). The principles of estimation of creatinine. Dtsch. Med. Wschr., 89: 1018, 1640.

Thadhani, R.;Pascual, M.; Bonventre, J.V. (1996) . Acute renal failure. N Engl $J$ Med., 334:1448-60.

Tomas\& Ganz. (2003). Hepcidin, a key regulator of iron metabolism and mediator of anemia of inflammation. Blood ., 102:783-788

Uchinos, $M$. (2005). Acute renal failure in critically ill patients :amultinational, multicenter study. JAMA; 204:813-18

Vijayakumar, M.; Nammalwar, B.and Prahlad, N. (2007). Prevention of chronic kidney disease in children. Indian journal of nephrology., 17:47-52.

Weinstein, D.A.;Roy, C.N.; Fleming, M.D.( 2002). Inappropriate expression of hepcidin is associated with iron refractory anemia: implications for the anemia of chronic disease. Blood. ,100: 3776-3781.

Weiss, G. and Goodnough, L.T. (2005). Anemia of chronic disease. $N$ Engl J Med., 352: 101123.

Yazar, H and Kayhan. (2010). Adult Hemodialysis Patients with End-stage Renal Disease and Erythropoietin Treatment of the Relation between Hypertension. $J$ Chem Pharm Res., 2: 588-93.

Zaritsky, J.; Young, B.; Wang ,H.J. (2009) .Hepcidin a potential novel biomarker for iron status in chronic kidney disease. ClinJAmSocNephrol ., 4: 1051-1056. 